\title{
Application of Modified BCR Sequential Extraction Method for the Fractionation and ICP-OES Determination of Copper in Asphaltite Combustion Waste
}

\author{
Firat Aydin ${ }^{a *}$, Beniz Gunduz ${ }^{b}$, Isil Aydin ${ }^{a}$, Osman Akba ${ }^{a}$, Abdurrahman Saydutc $^{c}$, \\ and Candan Hamamcia \\ a Dicle University, Science Faculty, Chemistry Department, 21280 Diyarbakir, Turkey \\ b Selcuk University, Faculty of Science, Chemistry Department, 42031 Konya, Turkey \\ ${ }^{\mathrm{c}}$ Dicle University, Engineering Faculty, Mining Engineering Department, 21280 Diyarbakir, Turkey
}

\section{INTRODUCTION}

Fossil fuel combustion waste contains many elements that may be released into the environment through fuel combustion processes and through leaching from disposed solid waste $(1,2)$. These elements exist in different forms which may change throughout the fuel combustion process (3-7). After the combustion process, the ash is often deposited in uncovered ash impoundments where it interacts with the surrounding environment. Rainwater leaches the toxic elements and carries them into rivers and to groundwater $(8,9)$. Wind-blown ash particles cover large areas with harmful dust and contaminate the land. For a better understanding of the risks associated with ash waste, speciation, solubility, and bioavailability of hazardous elements in waste products needs to be characterized (10-13). Chemical fractionation of $\mathrm{Cu}$ is a growing field of analysis as it helps to understand the true nature of this element in the environment as well as its biochemical pathways (14-17).

One of the most difficult problems encountered in speciation analysis is the development of an analytical procedure that does not disturb the chemical equilibria between the different forms of an element existing in a given matrix (18-22).

*Corresponding author.

E-mail:faydin@dicle.edu.tr

\section{ABSTRACT}

Asphaltite is derived from petroleum-origin solid fossil fuel. It contains many elements in different forms which may change during the combustion process. This study presents a modified BCR sequential extraction method for the fractionation of copper $(\mathrm{Cu})$ in asphaltite combustion waste (ACW) into four forms (exchangeable, reducible, oxidizable, and residual) and determination by inductively coupled plasma optical emission spectrometry (ICP-OES). The $327.393 \mathrm{~nm}$ line was used because it offers highest detectability and is free from major spectral interferences.

A two-stage microwave acid digestion program was used for preparation of the samples. The total $\mathrm{Cu}$ concentration in the ACW was $104.56 \mathrm{mg} \mathrm{kg}^{-1}$ dry weight (d.w). The most abundant copper fraction in the studied ACW samples was found as residual fraction of $\mathrm{Cu}$ (59.94 $\mathrm{mg} \mathrm{kg}^{-1}$ d.w.). The relative abundances of the remaining $\mathrm{Cu}$ fractions in ACW were as follows: exchangeable + water- and acid-soluble (19.07 $\mathrm{mg} \mathrm{kg}^{-1}$ d.w.) $>$ oxidizable $\left(17.49 \mathrm{mg} \mathrm{kg}^{-1}\right.$ d.w.) $>$ reducible $\left(7.65 \mathrm{mg} \mathrm{kg}^{-1}\right.$ d.w.). The results were found to be in good agreement with the certified values.

The advantages of the technique include a high degree of automation, good reproducibility, and short analysis time, which makes it the method of choice for the fractionation of $\mathrm{Cu}$.
Asphaltite is a petroleum-based solid fossil fuel and is formed by metamorphism associated with mineral matter. The combustion of asphaltites produces fly and bottom ashes which have a high content of valuable elements. After the combustion process, the ash is often deposited in uncovered ash impoundments, where it interacts with the surrounding environment. Processing of asphaltite causes environmental, industrial, and technological problems. A true understanding of the dynamics of elements in the natural environment requires an expanded knowledge of its oxidation-reduction in chemical reactions (23-26). Different veins of asphaltic materials have different physical and chemical characteristics depending on the location of asphaltite, geological formation, and the degree of metamophosis. The Silopi reserve was classified containing a substance between asphaltite and asphaltic pyrobitumen, while the Harbul vein (both in S.E. Anatolia, Turkey) contains the major part (approximately $2,5.107$ tons) of the Silopi asphaltites $(27,28)$. The material is used by power plants in the production of electrical energy (29). Thus, it is crucial to perform a complete chemical and mineralogical characterization of asphaltite combustion waste (ACW) in order to establish the contamination risk potential to the surrounding environment and to human health, as well as its possible industrial usage (30).

The development of a precise and simple determination method is essential to solve the problems 
due to the existence of metals in fuel (31-33). Atomic spectroscopy techniques such as X-ray fluorescence spectrometry (XRF), atomic absorption spectrometry (AAS), inductively coupled plasma optical emission spectrometry (ICP-OES), and inductively coupled plasma mass spectrometry (ICP-MS) are extensively used for Cu determination $(34,35)$.

Owing to the investigation of coal or petroleum-origin bitumen and pyrobitumen-containing formations around the world as an alter- native for the production of liquid/ gas fuel and chemical raw materials, the subject is of great interest in Turkey and studies concerning the determination and characterization of asphaltites have increased. The aim of this research was to investigate the total amount and distribution of $\mathrm{Cu}$ (exchangeable + waterand acid-soluble), iron and manganese oxides (reducible), organic matter and sulfides (oxidizable), and residual fractions in $\mathrm{ACW}$ from Silopi, Turkey.

TABLE I

ICP-OES Instrumental Operating Conditions

\begin{tabular}{|c|c|c|c|c|c|}
\hline \multicolumn{2}{|c|}{ Instrumentation } & \multicolumn{4}{|c|}{ PerkinElmer Optima ${ }^{\mathrm{TM}} 2100 \mathrm{DV}$} \\
\hline \multicolumn{2}{|l|}{ RF power } & \multicolumn{4}{|l|}{$1450 \mathrm{~W}$} \\
\hline \multicolumn{2}{|c|}{ Plasma gas flow rate } & \multicolumn{4}{|l|}{$15 \mathrm{~L} \mathrm{~min}^{-1}$} \\
\hline \multicolumn{2}{|c|}{ Auxiliary gas flow rate } & \multicolumn{4}{|l|}{$0.2 \mathrm{~L} \mathrm{~min}^{-1}$} \\
\hline \multicolumn{2}{|c|}{ Nebulizer gas flow rate } & \multicolumn{4}{|l|}{$0.8 \mathrm{~L} \mathrm{~min}^{-1}$} \\
\hline \multicolumn{2}{|c|}{ Sample flow rate } & \multicolumn{4}{|l|}{$1.5 \mathrm{~L} \mathrm{~min}^{-1}$} \\
\hline \multicolumn{2}{|l|}{ View mode } & \multicolumn{4}{|l|}{ Axial } \\
\hline \multicolumn{2}{|l|}{ Read } & \multicolumn{4}{|l|}{ Peak area } \\
\hline \multicolumn{2}{|c|}{ Source equilibration time } & \multicolumn{4}{|l|}{$15 \mathrm{~s}$} \\
\hline \multicolumn{2}{|c|}{ Read delay } & \multicolumn{4}{|l|}{$50 \mathrm{~s}$} \\
\hline \multicolumn{2}{|l|}{ Replicates } & \multicolumn{4}{|l|}{3} \\
\hline \multicolumn{2}{|c|}{ Background correction } & \multicolumn{4}{|c|}{ 2-point (manual point correction) } \\
\hline \multicolumn{2}{|l|}{ Spray chamber } & \multicolumn{4}{|c|}{ Scott type spray chamber } \\
\hline \multicolumn{2}{|l|}{ Nebulizer } & \multicolumn{4}{|c|}{ Cross-Flow GemTip ${ }^{\mathrm{TM}}$ nebulizer (HF resistant) } \\
\hline \multicolumn{2}{|l|}{ Detector } & \multicolumn{4}{|l|}{ CCD } \\
\hline \multicolumn{2}{|l|}{ Purge gas } & \multicolumn{4}{|l|}{ Nitrogen } \\
\hline \multicolumn{2}{|l|}{ Shear gas } & \multicolumn{4}{|l|}{ Air } \\
\hline Plasma gas & & Argon & & & \\
\hline Sample & $\begin{array}{r}\text { Preparatic } \\
\text { of }\end{array}$ & $\begin{array}{l}\text { TABLE II } \\
\text { n and Results o } \\
\text { he Harbul Asph }\end{array}$ & $\begin{array}{l}\text { Elemei } \\
\text { laltite }\end{array}$ & al Analyses & \\
\hline $\begin{array}{c}\text { Sample } \\
\text { Components }\end{array}$ & $\begin{array}{l}\text { Weight } \\
(\%)\end{array}$ & $\begin{array}{c}\text { Sulfur } \\
\text { Distribution }\end{array}$ & $\begin{array}{l}\text { Weight } \\
(\%)\end{array}$ & $\begin{array}{c}\text { Elemental } \\
\text { Analysis }\end{array}$ & $\begin{array}{l}\text { Weight } \\
\text { (\%) }\end{array}$ \\
\hline Moisture & 0.63 & Total Sulfur & 7.01 & Carbon & 54.07 \\
\hline Ash & 32.49 & Pyritic Sulfur & 1.50 & Nitrogen & 0.76 \\
\hline Fixed Carbon & 20.14 & Sulphate Sulfur & 0.26 & Hydrogen & 5.12 \\
\hline Volatile Matter & 46.74 & Organic Sulfur & 5.25 & & \\
\hline $\begin{array}{l}\text { HeatingValue } \\
\left(\mathrm{kcal} \mathrm{g}^{-1}\right)\end{array}$ & 6.276 & & & & \\
\hline
\end{tabular}

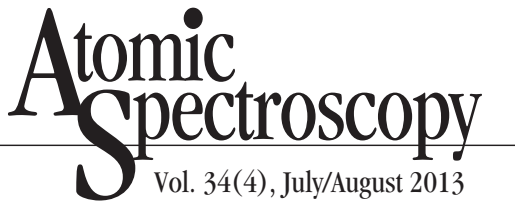

\section{EXPERIMENTAL}

\section{Instrumentation}

A Model Optima ${ }^{\mathrm{TM}} 2100$ DV inductively coupled plasma optical emission spectrometer (ICP-OES) (PerkinElmer, Inc., Shelton, CT, USA) was used to determine the different copper forms. The instrumental conditions were optimized to obtain sufficient sensitivity and precision and the instrumental parameters are listed in Table I. The spectral wavelength selected for the copper analyses was $327.393 \mathrm{~nm}$ because it provides minimum interference and maximum detection $(36,37)$.

\section{Reagents}

The reagents used were of Suprapur ${ }^{\circledR}$ grade (Merck \& Co., Darmstadt, Germany) or of analytical grade, and were used without further purification. Deionized water, $18 \mathrm{M} \Omega$, obtained with a Milli-Q ${ }^{\mathrm{TM}}$ system (Millipore Corporation, Bedford, MA, USA), was used throughout this study.

\section{Samples and Sample Preparation}

\section{Asphaltite Samples}

The asphaltite samples were obtained as lumps from the Harbul (Silopi) asphaltite field. A sample amount of about $10.0 \mathrm{~g}$ was ovendried (Memmert ULM 500, Memmert Gmbh + Co. KG, Schwabach, Germany) at $105^{\circ} \mathrm{C}$ and crushed with a jaw breaker (Model Retsch BB1/A, Haan, Germany), then ground in a rotor beater mill (Retsch SRZ, Haan, Germany). The particle sizes of the samples were sifted to less than $250 \mu \mathrm{m}$.

The results of the elemental analyses of the Harbul asphaltite are given in Table II. For the analysis, $10.0 \mathrm{~g}$ of asphaltite was put into a porcelain crucible and subjected to a calcination step in the muffle furnace at $950{ }^{\circ} \mathrm{C}$ for about six hours. 
Standard Reference Material

Standard reference material (SRM), NIST SRM-1633b Constituent Elements in Coal Fly Ash (National Institute of Standards and Technology, Gaithersburg, MD, USA) was used to check the accuracy of the analytical method. The results are listed in Table III together with the certified or reference values. The limit of quantitation (LOQ) for $\mathrm{Cu}$ of the ICP-OES measurements was $0.07 \mu \mathrm{g} \mathrm{L}^{-1}$, which is calculated as the concentration equal to 10 times the standard deviation of the background signal (the signal of the blank solution), multiplied by the dilution.

The SRM sample was dried in an oven at $105^{\circ} \mathrm{C}$ for three hours and stored over silicagel in a desiccator until analysis. The heating value, ash and sulfur content of the samples were determined according to the ASTM D 1103-80 procedures (9).

\section{Two-stage Digestion Procedure}

The two-stage microwave acid digestion procedure listed in Table IV was applied to the asphaltite samples. A 0.2-g portion of dried ACW sample was weighed and transferred into a pressure-resistant polytetrafluoroethylene (PTFE) vessel, and the acid mixture of $\mathrm{HNO}_{3}+\mathrm{HF}$ $(7: 2 \mathrm{~mL})$ added. The vessel was then sealed, mounted in a sleeve, and digested using the procedure in Step 1 of Table IV with a Berghof MWS-3 microwave digestion system (Berghof, USA). After step 1 was completed, the vessels were removed and cooled to room tem-

TABLE III

\begin{tabular}{l} 
Accuracy Assessment of Analysis \\
of NIST-1633b Constituent \\
Elements in Coal Fly Ash \\
Using Modified BCR Method \\
\hline
\end{tabular}

Ele- Certified Found Recovery ment $(\mathrm{mg} / \mathrm{kg}) \quad(\mathrm{mg} / \mathrm{kg}) \quad(\%)$

$\mathrm{Cu} 112.8 \pm 2.6 \quad 113.4 \pm 0.9 \quad 100.5$ perature in a waterbath. The procedure and acid conditions of the first process were the same as those for the one-stage digestion except for the digestion program. After the venting procedure mentioned above, $\mathrm{H}_{3} \mathrm{BO}_{3}(15 \mathrm{~mL})$ was quickly added to each sample. Crystallization of $\mathrm{CaF}_{2}$ was avoided by addition of boric acid. The vessels were returned to the microwave digestion system and the second step was applied to the sample under the conditions described in Table IV, step 2. The power applied was $1450 \mathrm{~W}$. The reaction mixture was

TABLE IV Operating Conditions for Two-Stage Digestion by Microwave Oven

\begin{tabular}{lrrr}
\hline Step 1 & & & \\
$\mathrm{T}^{\circ} \mathrm{C}$ & 140 & 160 & 190 \\
${\text { WT }(\min )^{\mathrm{a}}}^{\mathrm{T}}$ & 5 & 3 & 5 \\
Time $(\min )^{\mathrm{b}}$ & 5 & 10 & 20 \\
\hline
\end{tabular}

\begin{tabular}{lrr}
\hline Step 2 & & \\
$\mathrm{T}^{\circ} \mathrm{C}$ & 160 & 100 \\
${\text { WT }(\min )^{\mathrm{a}}}^{\mathrm{a}}$ & 3 & 1 \\
Time (min) & 15 & 15 \\
\hline
\end{tabular}

${ }^{\mathrm{a}} \mathrm{WT}(\mathrm{min})=$ Waiting time at desired temperature.

$\mathrm{b}$ Time $(\mathrm{min})=$ Time between the two successive temperatures. subjected to an evaporation method in order to remove the acids by the use of an evaporation module after the final digestion. Then the residue was dissolved in Milli-Q ${ }^{\mathrm{TM}}$ water and filtered through a $0.45 \mu \mathrm{m}$ GF/C filter membrane (Sartorius AG, Göttingen, Germany), and the filtrate diluted to $50 \mathrm{~mL}$.

\section{Sequential Extraction Procedure}

The Commission of the European Communities Bureau of Reference (BCR), based on the schemes of Salomons and Forstner, is a sequential extraction method widely used for the evaluation of availability and mobility of trace metals (35). In this study, the sequential extraction was performed using a revised BCR protocol (Bureau Communautaire de Reference) recommended in previous studies $(12,20)$ as follows: The revised BCR scheme applied (see Figure 1) is a four-step sequential procedure, using an increase in the concentration of $\mathrm{NH}_{2} \mathrm{OH} \cdot \mathrm{HCl}$ (0.5M, pH = $1.5 \pm 0.2)$ (12). It was based on an acetic acid extraction of approximately $1 \mathrm{~g} \mathrm{ACW}$ (step 1), hydroxylamine hydrochloride extraction (step 2), and hydrogen peroxide oxidation and ammonium acetate extraction (step 3). These extractions are associated to the exchangeable + water- and acidsoluble phase (bound to carbonate, step 1), the reducible phase (bound

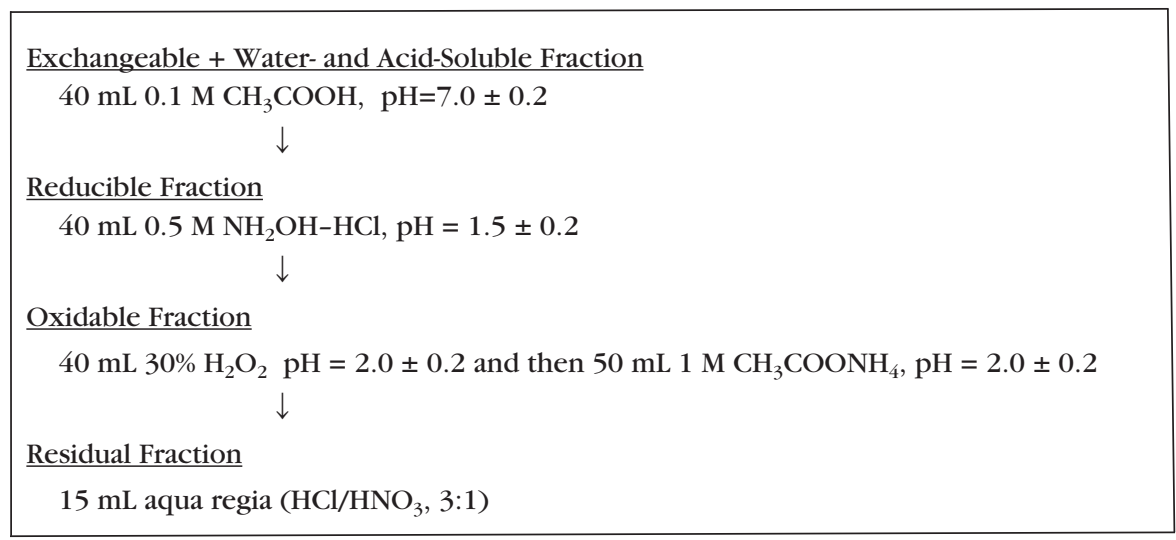

Fig 1. The concentration of different copper fractions was determined using the modified sequential extraction procedure in asphaltite combustion waste. 
to iron and manganese oxides, step 2), and the oxidizable phase (bound to organic matter step 3). In an asphaltite combustion waste, copper bound to sulfide is mainly leached (step 3). To extract the residual phase (step 4), a mixture of $2.5 \mathrm{~mL} \mathrm{HNO}_{3}(65 \%)$ and $7.5 \mathrm{~mL}$ $\mathrm{HCl}$ (37\%) (aqua regia digestion) was added to the residue and the filter from fraction 3. After microwave destruction, the samples of step 4 were paper-filtered with a $0.45 \mu \mathrm{m}$ $\mathrm{GF} / \mathrm{C}$ filter membrane and diluted to $100 \mathrm{~mL}$ with ultrapure water. The extracts were centrifuged and the supernatants filtered through a $0.45 \mu \mathrm{m} \mathrm{GF} / \mathrm{C}$ filter membrane (Sartorius AG, Göttingen, Germany). Each sample was handled in triplicate. The soluble $\mathrm{Cu}$ in each sample was determined by ICP-OES.

\section{RESULTS AND DISCUSSION}

This study presents the concentration and fractionation of copper in combustion waste of asphaltite from Silopi, SE Anatolia, Turkey. Fractionation of $\mathrm{Cu}$ was carried out using a revised BCR method (17) based on the sequential extractions from the $\mathrm{ACW}$ of four $\mathrm{Cu}$ forms; acid-extractable, reducible, oxidizable, and residual fractions (see Figure 1). Asphaltite combustion waste (ACW), the inorganic residue derived from the burning of asphaltite, represents the non-combustible impurities originally present in asphaltite $(3,7)$. Application of the sequential extraction procedure to ACW provides relevant information about possible toxicity when $\mathrm{Cu}$ is discharged into the environment.

The total concentration of $\mathrm{Cu}$ of all phases was compared with the certified values of NIST SRM 1633b Constituent Elements in Fly Ash and the values obtained from the total digestion.

Microwave-acid digestion (MWAD), followed by inductively coupled plasma optical emission spectrometry (ICP-OES), was exam- ined for the determination of total $\mathrm{Cu}$ in ACW. Dry ashing was used for the almost complete elimination of the organic materials prior to analyte determination. The particle sizes of the samples were smaller than $0.071 \mathrm{~mm}$, and an ashing temperature of $950^{\circ} \mathrm{C}$ was found to be the best as a result of the trade-off between the overall $\mathrm{Cu}$ recovery yield (30). Wet acid digestion ( $\mathrm{HCl}$, $\mathrm{HNO}_{3}, \mathrm{H}_{3} \mathrm{BO}_{3}$ ) was used for $\mathrm{Cu}$ determination in ACW. Crystallization of $\mathrm{CaF}_{2}$ is avoided by addition of boric acid. The two-stage digestion was carried out and is listed in Table IV.

Optimum line selection for trace analysis implies choosing the prominent lines with minimum value of the true detection limit, i.e., those with lowest line interference and background (wing) interference signals in the presence of the matrix (31-37). The results for the standard reference material NIST SRM1633b listed in Table III are in good agreement with the ACW values (Table V). The total measured concentration of $\mathrm{Cu}$ in ACW was $104.56 \mathrm{mg} \mathrm{kg}^{-1}$ d.w. Although the total concentration of $\mathrm{Cu}$ is still useful in many areas, the knowledge of speciation is of primary importance because the toxicity, mobility, bioavailability, and bioaccumulation depend on the chemical species. As can be seen in Table V, the most abundant form of $\mathrm{Cu}$ in $\mathrm{ACW}$ is the residual fraction (step 4) $\left(59.94 \mathrm{mg} \mathrm{kg}^{-1}\right.$ d.w.) which is safer for the environ-

\section{Atomic Apectroscopy 1 Vol. 34(4), July/August 2013}

ment due to its low mobility and bioavailability.

\section{Exchangeable + Water- and Acid-Soluble Fraction}

The exchangeable + water- and acid-soluble fraction in ACW is the most dangerous for the environment (38). This fraction shows an increase in the amount of $\mathrm{Cu}$ that would be released into the environment when conditions become more acidic, and may be present as co-precipitate with carbonate minerals and strong-sorbed metal forms on the ash surface. The fraction is sensitive to $\mathrm{pH}$ changes, and $\mathrm{Cu}$ release can be achieved through dissolution of a fraction of the solid material at a low $\mathrm{pH}$. Copper in the exchangeable fraction plays a very important role in the evaluation of the environment and always acts as a pollution indicator for its environmental mobility and bioavailability (39). Usually the weakly sorbed $\mathrm{Cu}$ forms, particularly those retained on the ash surface by relatively weak electrostatic interactions, are included in this operational fraction. This fraction is the most active part to pose an environmental risk to humans and the biomass. Fortunately, the amount and proportion of $\mathrm{Cu}$ extracted in this fraction in ACW is low (18.24\%), which is consistent with its chemistry of being predominantly bound as sulfides and does not dissolve from asphaltite combustion waste at this stage.

TABLE V

Concentration of Total and Species of Copper in Asphaltite Combustion Waste Using Modified BCR Method

\begin{tabular}{lc}
\hline Copper & $(\mathrm{mg} / \mathrm{kg})$ \\
\hline Total Cu & $104.56 \pm 1.89$ \\
Exchangeable + Water- and Acid-Soluble Fraction & $19.07 \pm 0.87$ \\
Reducible Fraction & $7.65 \pm 0.52$ \\
Oxidable Fraction & $17.49 \pm 0.94$ \\
Residual Fraction & $59.94 \pm 1.16$ \\
\hline
\end{tabular}




\section{Reducible Fraction}

The reducible fraction of $\mathrm{Cu}$ in the revised BCR scheme used in this study represents the $\mathrm{Cu}$ bound to iron (Fe) and manganese (Mn) oxides and would be released if the substrate is subjected to more reductive conditions. However, this fraction is the lowest $\mathrm{Cu}$ amount in this organic-rich reduced ACW. The revised $B C R$ technique produces negligible concentrations of the reducible fraction of $\mathrm{Cu}(7.32 \%)$. It was found that the metals bonded to sulfide can be extracted in the reducible fraction of ACW. Sulfide solid phases are dissolved in various extraction steps along the extraction sequence and not only in the "sulfide" fraction (40). However, it was found that it releases substantial amounts of copper bound to the organic matter/sulfides fraction.

\section{Oxidizable Fraction}

The oxidizable fraction shows the amount of copper bound to the organic matter and sulfur which would be released into the environment if conditions became oxidative (39-41). Most metals readily form compounds with sulfur. The sulfur-binding fraction is normally stable with respect to temperature and low $\mathrm{pH}$. The $\mathrm{Cu}$ in this fraction is more stable and will take part in the geochemical cycle less easily. Yet, it will become labile when the oxide reduction conditions have changed. Under the oxidizing conditions, the organic materials and the reducing sulfur compounds may be destroyed, and the $\mathrm{Cu}$ associated with them can leach into the environmental water system. The percentage of copper in the oxidizable (organic matter and sulfides) fraction was $16.73 \%$ of the total copper extracted. This does not imply that the $\mathrm{Cu}$ in this fraction does not pose a threat to the environment and is, therefore, always a potential source of pollution.

\section{Residual Fraction}

The residual fraction represents the copper that has the strongest association with the crystalline structures of the minerals. It is not always easy to extract copper in this fraction. A much higher percentage of copper $(57.33 \%$ of the total metal extracted) was found in the residual fraction using the modified BCR scheme than the other fractions. The $\mathrm{Cu}$ compounds are mainly bound to the organic matter/sulfides and residual fractions (74.06\% of total copper extracted). The modified BCR sequential extraction procedure suggested in this study can also be used to provide useful information for migration assessment in ACW, since the amounts of copper mobilizable under different changes in environmental conditions can be determined.

\section{CONCLUSION}

Copper is an element characteristically associated with airborne particulates originating from asphaltite combustion. Assessment of chemical, mineralogical, morphological, and leaching behavior of ashes is important for effective environmental waste management.

In the present work, a modified BCR (Bureau Communautaire de Reference) sequential extraction procedure was applied to asphaltite combustion waste (ACW) samples obtained from Harbul, Silopi, Turkey, with different degradations for fractionation of copper. Fractionation was carried out to determine four forms of $\mathrm{Cu}$ by ICP-OES: exchangeable + water- and acidsoluble, reducible, oxidizable, and residual fractions. The most abundant form of $\mathrm{Cu}$ in $\mathrm{ACW}$ is the residual fraction $\left(59.94 \mathrm{mg} \mathrm{kg}^{-1}\right.$ d.w). The relative abundances of the remaining $\mathrm{Cu}$ fractions in ACW were found as follows: exchangeable + water- and acid- soluble (19.07 $\mathrm{mg} \mathrm{kg}^{-1}$ d.w.) > oxidizable (17.49 $\mathrm{mg} \mathrm{kg}^{-1}$ d.w.) > reducible ( $7.65 \mathrm{mg} \mathrm{kg}^{-1}$ d.w.).

The proposed sequential extraction scheme is sufficiently repeatable and reproducible for application in fractionation studies. The advantages of the technique include high degree of automation, good reproducibility, and short analysis time. The results presented in this article imply that the proposed modified BCR sequential extraction method can be used to identify qualitative differences in the partitioning of $\mathrm{Cu}$ in $\mathrm{ACW}$.

Received April 29, 2013.

\section{REFERENCES}

1. I. Aydin, F. Aydin, and C. Hamamci., Fuel 95, 481 (2012).

2. F. Aydin, A. Saydut, B. Gunduz, I. Aydin, and C. Hamamci., Clean Soil, Air, Water, 40, 444 (2012).

3. P. Norris, C.W. Chen, W.P. Pan, Anal. Chim. Acta 663, 39 (2010).

4. M. Sert, L. Ballice, M. Yuksel, and M. Saglam, Fuel 90, 2767 (2011).

5. I. Aydin, F. Aydin, and C. Hamamci, Microchem. J. 108, 64 (2013).

6. F. Aydin, A. Saydut, I. Aydin, and C. Hamamci, At. Spectrosc. 32, 194 (2011).

7. A. Saydut, M. Z. Duz, I. Aydin, and C. Hamamci, Energ. Explor. Exploit. 26, 133 (2008).

8. S.Tokalıglu and S.Kartal, Bull. Environ. Contam. Toxicol. 75,180 (2005).

9. M.Z. Duz, S. Erdogan, A. Saydut, M. Merdivan, and C. Hamamci, Energ. Sour, Part A, Recov. Utilization Environm. Eff. 30, 1637 (2008)

10. B. Gunduz , F. Aydın, I. Aydın, and C. Hamamci, Microchem. J. 98, 72 (2011).

11. D. Bakircioglu,Y.B. Kurtulus,H. Ibar, Clean - Soil, Air, Water, 39, 728 (2011). 


\section{Atomic $_{\text {Spectroscopy }}^{\text {to }}$ \\ 1 Vol. 34(4), July/August 2013}

12. K.F. Mossop and C.M. Davidson, Anal. Chim. Acta 478, 111 (2003).

13. C. Hamamci, and B. Ziyadanogullari, Sep. Sci Technol. 26, 1147 (1991).

14. G. Rauret, J.F. Lopez-Sanchez, A. Sahuquillo, E. Barahona, M. Lachica, A.M. Ure, C.M. Davidson, A. Gomez, D. Luck, J. Bacon, M. Yli-Halla, H. Muntau, and Ph. Quevauviller, J. Environ. Monit. 2, 228 (2000).

15. B. Gunduz, I. Aydin, S. Bakirdere, A. Saydut, and F. Aydin, At. Spectrosc. 31, 196. (2010)

16. K.N. Buck, J. R.M. Ross, A. R. Flegal, and $\mathrm{K}$. W. Bruland, Environ. Res. 105, 5 (2007).

17. E. D. van Hullebusch, S. Utomo, M. H. Zandvoort, and P.N.L. Lens, Talanta 65, 549 (2005)

18. T. Jong, and D.L. Parry, J. Environ. Monit. 6, 278 (2004)

19. B. Perez-Cid, I. Lavilla, and C. Bendicho, Analyst 121, 1479 (1996).

20. C.M. Davidson, R.P. Thomas, S.E. McVey, R. Perala, D. Littlejohn, and A.M. Ure, Anal. Chim. Acta 291, 277 (1994).

21. J. Lacal, M.P. Da Silva, R. Garcia, M.T. Sevilla, J.R. Procopio, and L. Hernandez, Environ. Poll. 124, 291 (2003).

22. M. Soylak, U. Uzak, I .Narin, M. Tuzen, O. Turkoglu, L. Elci, Fres. Environ. Bull.13, 457 (2004).

23. C. Hamamci, M.Z. Duz, A. Saydut, and M. Merdivan, Oil Shale 20, 161 (2003).

24. O. Kavak, Fuel 90, 1575 (2011).

25. A. Saydut, M.Z. Duz, Y. Tonbul, A. Baysal, and C. Hamamci, J. Anal. Appl. Pyrol. 81, 95 (2008).

26. M.V. Kok, J. Therm. Anal. Calorim. 88, 663 (2007).

27. Y. Tonbul, A. Saydut, and C. Hamamci, Oil Shale 23, 286 (2006).

28. A. Saydut, M.Z. Duz, and C. Hamamci, Oil Shale 24, 476 (2007).

29. A. Saydut, Y. Tonbul, and C.Hamamci, Energ. Explor. Exploit. 26(1), 23 (2008).
29. D. Quispe, R.P. López, L.F.O. Silva, and J.M. Nieto, Fuel 94, 495 (2012).

30. I. Aydin, F. Aydin, A. Saydut, E.G. Bakirdere, and C. Hamamci, Microchem. J. 96, 247 (2010).

31. I. Aydin, F. Aydin, E. Kilinc, and C. Hamamci, Oil Shale 27, 331 (2010).

32. F. Aydin, I. Aydin, S. Erdoğan, O. Akba, B. Isik, and C. Hamamci, Pol. J. Environ. Stud. 21, 533. (2012).

33. M. Zemberyova, J. Bartekova, and I. Hagarova, Talanta 70, 973 (2006).

34. M.Z. Duz, K.S. Celik, I. Aydin, S. Erdogan, F. Aydin, and C. Hamamci, At. Spectrosc. 33, 78 (2012).

35. W. Salomons, U. Forstner, Metals in the Hydrogeocycle, Springer Verlag, Berlin, Germany (1984).

36. O. Akba, A. Baysal, C. Hamamci, M. Merdivan and B. Gumgum, Asian J. Chem. 17, 1518 (2005)

37. A.K. Krishna, K.R. Mohan, N.N. Murthy, At. Spectrosc. 30, 75 (2009).

38. K. Nemati , N. Kartini A. Bakar, E. Sobhanzadeh, and M. R. Abas, Microchem. J. 92, 165 (2009).

39. Y.Y. Long, L.F. Hu , C.R. Fang, Y.Y. Wu, and D. S. Shen, Microchem. J. 91, 1 (2009).

$40 \mathrm{~K}$. Wallman, M. Kersten, J. Gruber, and U. Forstner, Int. J. Environ. Anal. Chem. 51, 187 (1993). 